\title{
Sertoli-Leydig Cell Tumor from Latifa Hospital, Dubai UAE: Case Report
}

\author{
Z. Almahloul, A. B. Fazari*, L. Paulose, Z. Nagshabandi, T. Gergawi \\ Latifa Hospital Dubai Health Authority, Dubai, UAE \\ Email: ^atiffazari@hotmail.co.uk
}

How to cite this paper: Almahloul, Z., Fazari, A.B., Paulose, L., Nagshabandi, Z. and Gergawi, T. (2020) Sertoli-Leydig Cell Tumor from Latifa Hospital, Dubai UAE: Case Report. Open Journal of Obstetrics and Gynecology, 10, 319-325.

https://doi.org/10.4236/ojog.2020.1020028

Received: January 4, 2020

Accepted: February 25, 2020

Published: February 28, 2020

Copyright $\odot 2020$ by author(s) and Scientific Research Publishing Inc. This work is licensed under the Creative Commons Attribution International License (CC BY 4.0).

http://creativecommons.org/licenses/by/4.0/

\begin{abstract}
Sertoli-Leydig cell tumors (SLCTs) are rare tumors. Mass and pain are the presenting feature. The varying histopathology and differentiation of this tumor present difficulties with proper diagnosis and development of optimal treatment regimens. The prognosis depends on tumors grading and staging. Surgery is main stay management option. Chemotherapy and radiation options are still of choice. We aimed to present Sertoli-Leydig cell tumor managed surgical at Latifa Hospital in Dubai, UAE with acceptable outcome and good patient satisfaction.
\end{abstract}

\section{Keywords}

Ovarian Tumors, Sertoli-Leydig Cell Tumors, Clitoromegaly, Virilization

\section{Introduction}

Sertoli-Leydig cell tumors (SLCTs) are rare tumors, accounting for less than $0.5 \%$ of all ovarian cancers. The varying histopathology and differentiation of this tumor present difficulties with proper diagnosis and development of optimal treatment regimens [1]. Very few case reports have been documented in the literature so far [2].

Prognosis of ovarian SLCTs is significantly correlated with degree of tumor grading and staging. Management of ovarian SLCTs remains challenging owing to lack of standardized management protocol guidelines [3].

Surgical resection represents the mainstay of management of ovarian SLCTs [4]. The role of postoperative chemotherapy remains questionable and is only indicated in patients with poor prognostic factors [2].

We report the case of a Sertoli-Leydig cell tumor found in a 19-year-old female with intermediate differentiation and heterologous elements (mainly epithelial components: gastrointestinal, hepatocellular and respiratory), with intact 
capsule of the right ovary.

\section{Case Report}

19 years old, Unmarried, University student referred from primary health center as case of secondary amenorrhea for 1 year with pelvic mass. This amenorrhea has been preceded by irregular periods for 6 months in pattern of irregular prolonged bleeding, acne, increase body hair and horsiness of voice).

No other systematic symptoms and normal urinary and bowel habits.

Gynecologic history: menarche age 14 years, periods were regular 5/30 days, normal flow, no dysmenorrheal.

Medical history: no chronic disease is reported and surgical intervention before, she is free from and medication nor allergy.

\section{On Physical Examination}

Normal body configuration with body mass index $=24.3$. Stable vital signs no paler.

Obvious acne on face and shoulder. Limitation to assess hirsutism on face due to laser treatment, few dark thick hairs on the breast and around the umbilicus.

Normal breast size and shape (She noticed both are less in size than before, may started some atrophy).

Abdominal palpation reveals abdomino-pelvic mass felt up to umbilicus around $20 \mathrm{~cm}$ size, regular surface, hard, immobile, no tenderness.

There is clear Clitoromegaly about $3 \mathrm{~cm}$ length.

Because of virginity no per vagina nor speculum examination performed.

Table 1 shows the results of the requested blood tests investigations reflecting high alfa fetoprotein, free androgen and testosterone.

Table 1. Shows the case's investigations highlighting the abnormal ones.

\begin{tabular}{ccc}
\hline Test & Value & Comment \\
\hline LH & $4.2 \mathrm{miu} / \mathrm{ml}$ & normal \\
FSH & $<0.4 \mathrm{miu} / \mathrm{ml}$ & -low \\
Estradiol & $199 \mathrm{pmol} / \mathrm{l}$ & normal \\
Prolactin & $197 \mathrm{miu} / \mathrm{l}$ & normal \\
Total testosterone & $16.5 \mathrm{nmol} / 1$ & high (normal up 2.9) \\
Free androgen & 56.9 & high (normal up to 6) \\
17 hydroxyprogesterone & $21 \mathrm{nmol} /$ & normal \\
DHE-sulfate & $117 \mathrm{ug} / \mathrm{dl}$ & normal \\
CA125 & $18.6 \mathrm{u} / \mathrm{ml}$ & high \\
AFP & $215 \mathrm{IU} / \mathrm{ml}$ & \\
LDH & $175 \mathrm{U} / \mathrm{L}$ & \\
HCG & $<5 \mathrm{~m} \mathrm{IU/ml}$ & \\
CA19-9 & $4.7 \mathrm{u} / \mathrm{ml}$ & \\
& & \\
& &
\end{tabular}


Ultrasound scan for the pelvis and the abdomen was done, Figure 1; the following report was obtained.

1) Uterus: Anteverted normal size uterus with Endometrium: measures $7 \mathrm{~mm}$ in thickness.

2) Left ovary: $2.3 \mathrm{~cm} \times 1.5 \mathrm{~cm} \times 1.8 \mathrm{~cm}$ Volume $3.4 \mathrm{cc}$.

3) Right ovary. huge in size $13.4 \mathrm{~cm} \times 8 \mathrm{~cm} \times 11.8 \mathrm{~cm}$ respectively preoccupied with multiseptated cystic lesion (thick septa $>3 \mathrm{~mm}$ ) and frank solid component. There is flow within the solid component seen on Doppler interrogation.

Magnetic resonance images showed large pelvic-abdominal mass lesion arising from the right ovary mixed cystic/solid mass lesion measuring $16 \times 8 \times$ $13 \mathrm{~cm}$ with multiple septa noted. The lower part of the lesion shows hyper intense signal intensity consistent with hemorrhagic component. Irregular thickening of the septae with few small irregular mural soft nodules. In post contrast series, there is intense enhancement of the wall and septae with solid part of the lesion noted. No obvious infiltration into surrounding tissues noted. Left ovary appears normal. The uterus is retroverted with homogenous myometrium noted. No lymphadenopathy or pelvic collection noted. Figure 2, Computerized tomography of the abdomen and chest has normal anatomical findings.

Through discussion and patient counseling with patient a decision for laparotomy was made and Right salpingo-oophorectomy was performed Figure 3. Intraoperative findings of laparotomy: Right ovarian mass $(15 \times 20 \mathrm{~cm})$, cystic and solid in consistency. Not adherent to the bowel or the pelvis. It was removed intact. Engorged right pelvic veins. Normal left ovary and tube. Normal sized uterus. Right pelvic lymph node $(1-2 \mathrm{~cm})$. Normal omentum, appendix, liver surface and upper abdomen. She tolerated the surgery well and spent uneventful post-operative period.

The histopathology report proved Sertoli-Leydig cell tumor of ovary, moderately differentiated (intermediate grade), with heterologous elements (mainly epithelial components: gastrointestinal, hepatocellular and respiratory), with

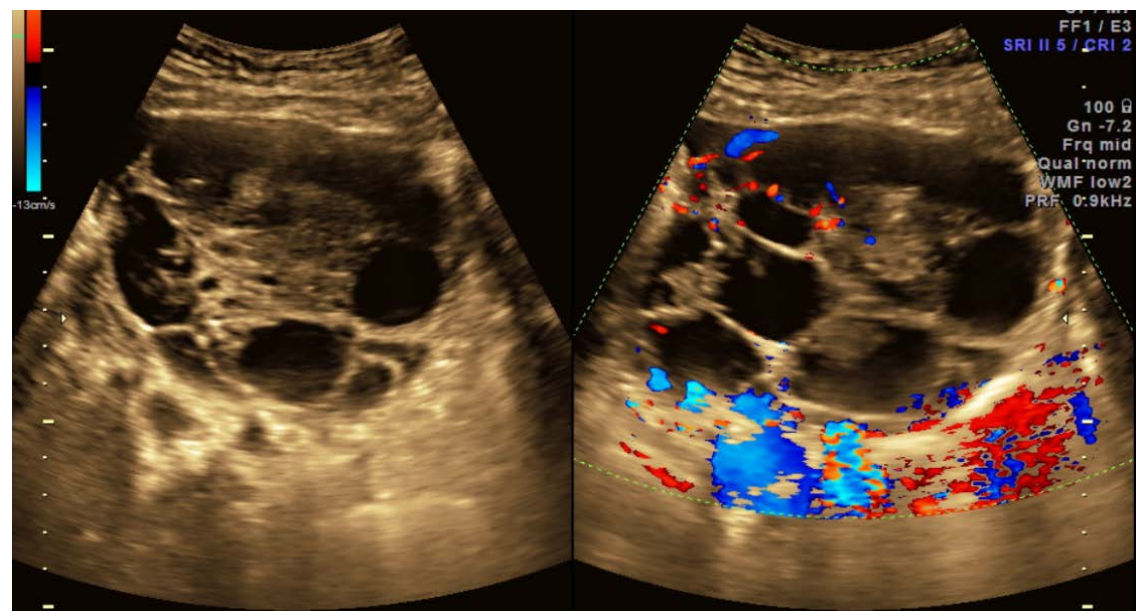

Figure 1. Ultrasound scan of the right ovary. 


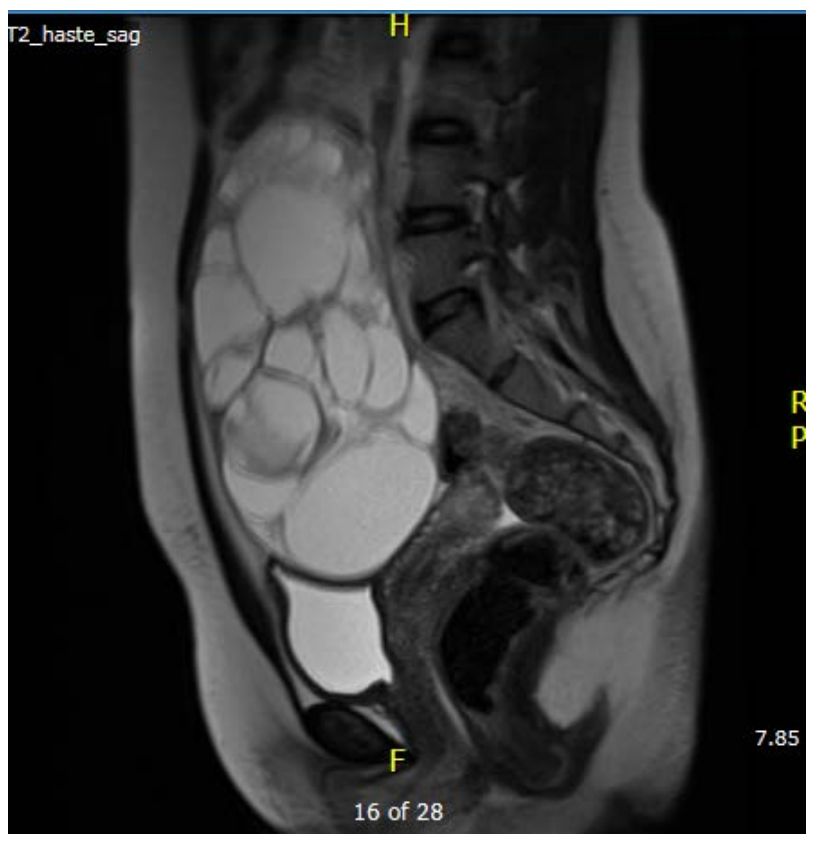

Figure 2. Pelvic Magnetic resonance images.

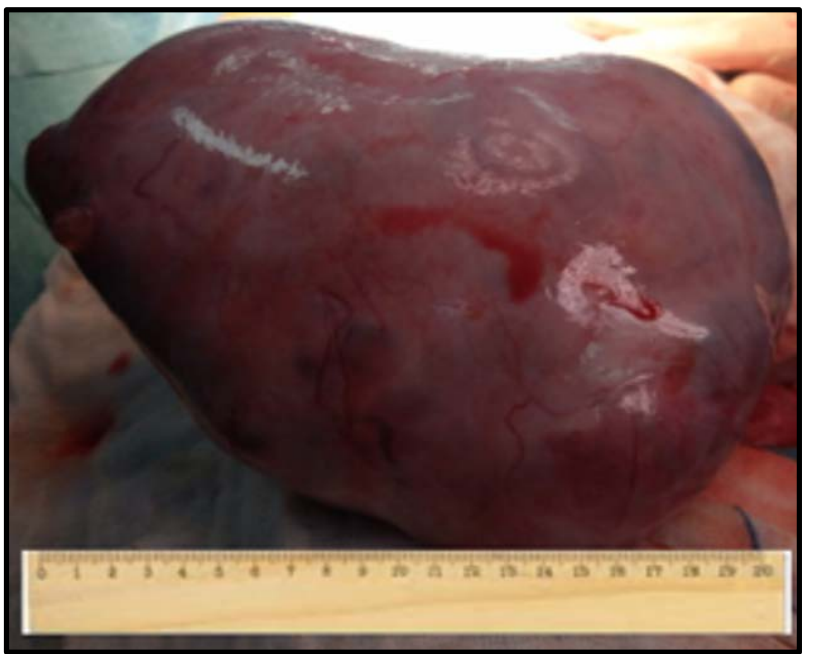

Figure 3. The specimen of the right salpingo-oophorectomy.

intact capsule, measuring $18.0 \times 13.0 \times 10.0 \mathrm{~cm}$, and confined to the "right" ovary. The fallopian tube is free of tumor. No tumor rupture nor spread outside the ovary are identified. No necrosis nor hemorrhage seen. No sarcomatoid changes are seen. No carcinomatous changes are seen. Figure 4:

No further treatment needed she had been under follow up for three months She resumes her period in regular way after one month. Clitoris enlargement improved from $3 \mathrm{~cm}$ to $0.5 \mathrm{~cm}$, with very accepted improvement in the acne and hair distribution

\section{Discussion}

Sertoli-Leydig cell tumors have range of symptoms and signs related to either 


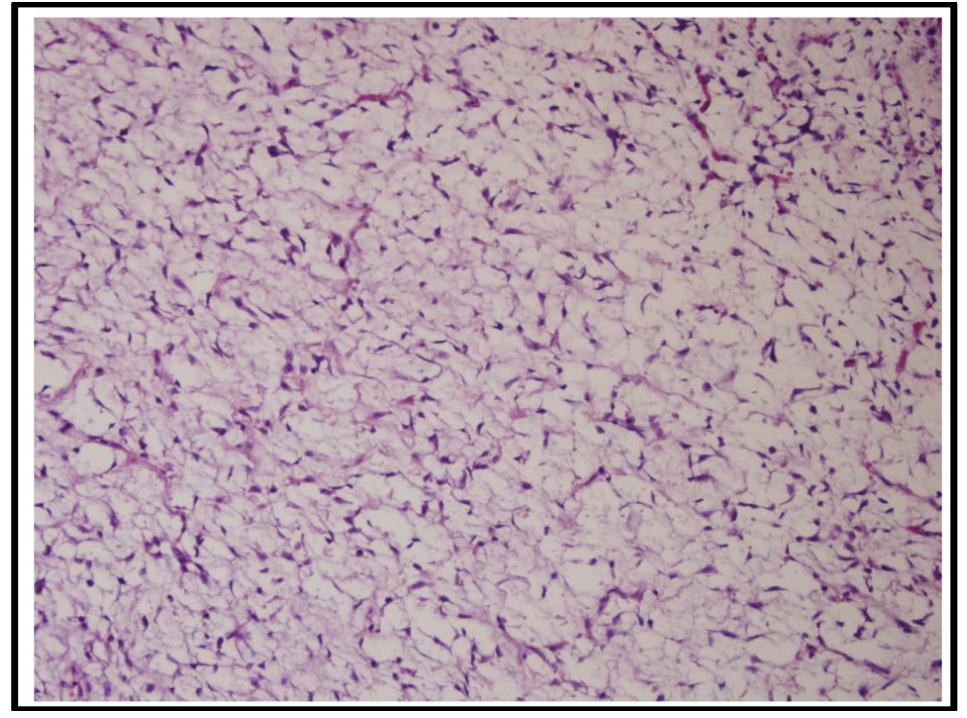

Figure 4. Histopathology slide shows moderately differentiated Sertoli-Leydig cell tumor with heterologous elements mainly epithelial components.

mass-lesion or expression of hormonal production. The hormonal expression can be identified in more than half of patients. Clinical expression of virilization is recognized in more than one-third $(33 \%-38 \%)$ of patients [4]. Androgen-excess manifestations with varying degrees include virilism, hirsutism, hyperseborrhea, acne, receding hairline, alopecia, hoarseness of voice, loss of subcutaneous tissue deposits, breast atrophy, clitoromegaly, oligomenorrhea and amenorrhea our case here presented typically with some common features of Androgen-excess manifestations. Conversely, although rare, estrogen-excess manifestations include precocious puberty, abnormal uterine bleeding, abnormal vaginal bleeding, menstrual irregularities, generalized edema, weight gain, breast hypertrophy, endometrial hyperplasia, endometrial polyps and endometrial carcinoma.

This case has elevated serum levels of testosterone although elevated serum levels of testosterone and androstenedione can be often identified in approximately $80 \%$ of patients with ovarian SLCTs and virilizing manifestations [4]. Testosterone serum levels greater than $200 \mathrm{ng} / \mathrm{dL}(7 \mathrm{nmol} / \mathrm{L})$ are generally associated with an androgen-secreting neoplasm from ovaries, adrenals, or elsewhere, in this case is $16.5 \mathrm{nmol} / \mathrm{l}$.

Almost half of the cases has classical presentation of pain or abdominal/pelvic mass which is unilateral with range of movement. The features of chronic pelvic pain is due to expansion of the mass capsule and acute pain is happened in minority of cases most properly due to ovarian accident in form of mass torsion. Acute abdominal pain requiring prompt emergency intervention happens in roughly less than one-fifth (15\%) of SLCT cases and can be attributable to ovarian torsion, capsular rupture, or bleeding [5].

Sonography (ultrasound) remains the best imaging modality of preference for initial assessment of adnexal masses, due to its high sensitivity, suitability, and 
cost-effectiveness [6]. We do suggest color Doppler sonography for all ovarian mass cases which might help in evaluation of neoplastic masses. Rich ovarian vascular masses with low-resistance indices in favor of malignant rather than benign lesions.

Other imaging modalities such as computed tomography (CT), magnetic resonance imaging (MRI), and positron imaging tomography (PET) scans can be used for better characterization of ovarian SLCTs, detection of extraovarian disease/metastasis and identification of other possible primary neoplasms (e.g., a functional androgen-producing adrenal gland tumor).

In histopathology study SLCTs are classically made up of uncontrolled proliferation of varying degrees of differentiation of tubules lined by Sertoli cells and intervening nests of Leydig cells. Well-and moderately differentiated SLCTs are the most frequently encountered histological variants. [7] Our case gives more or less same features that finalize the diagnosis. Further immunohistochemically may be needed.

Surgery remains the modality of choice for the case management, based on patient age, fertility issues, clinical presentation, tumors markers and histopathology this surgery might include: cystectomy, oophorectomy, total abdominal hysterectomy plus bilateral salpingoopherectomy, lymphadenectomy as well further oncology treatment still is part of management.

\section{Conclusion}

Sertoli-Leydig cell tumors are rare tumors, have range of symptoms and signs related to either mass-lesion or expression of hormonal production. Surgery remains the modality of choice for the case management.

\section{Acknowledgements}

Special thanks for Latifa Administration, ObsGyn department, theater staff, nursing staff and Dr. Lakshmiah Raman histopathologist for the cooperation.

\section{Disclosure}

No disclosure.

\section{Conflicts of Interest}

None of the authors has conflict of interest.

\section{References}

[1] Casandra, A., Liggins, Ly.T. and MaMatthew, P. (2016) Schlumbrecht Sertoli-Leydig Cell Tumor of the Ovary: A Diagnostic Dilemma. Gynecologic Oncology Reports, 15, 16-19. https://doi.org/10.1016/j.gore.2015.12.003

[2] Abu-Zaid, A., Azzam, A., Alghuneim, L.A., Metawee, M.T., Amin, T. and Al-Hussain, T.O. (2013) Poorly Differentiated Ovarian Sertoli-Leydig Cell Tumor: A Case Report and Literature Review. Case Reports in Obstetrics and Gynecology, 2013, Article ID 858501. https://doi.org/10.1155/2013/858501 
[3] Bhat, R.A., Lim, Y.K., Chia, Y.N. and Yam, K.L. (2013) Sertoli-Leydig Cell Tumor of the Ovary: Analysis of a Single Institution Database. Journal of Obstetrics and Gynaecology Research, 39, 305-310. https://doi.org/10.1111/j.1447-0756.2012.01928.x

[4] Weng, C.S., Chen, M.Y., Wang, T.Y., et al. (2013) Sertoli-Leydig Cell Tumors of the Ovary: A Taiwanese Gynecologic Oncology Group Study. Taiwanese Journal of $O b$ stetrics \& Gynecology, 52, 66-70. https://doi.org/10.1016/j.tjog.2012.03.001

[5] Zanotti, K.M. (2002) The Clinical Manifestations and Diagnosis of Sertoli-Leydig Cell Tumors of the Ovary. CME Journal of Gynecologic Oncology, 7, 129-133.

[6] de Oliveira Franzin, C.M., Kraft, M.L., Faundes, D., Zeferino, L.C., Alvarenga, M. and Marussi, E.F. (2006) Detection of Ovarian Sertoli-Leydig Cell Tumors Exclusively by Color Doppler Sonography. Journal of Ultrasound in Medicine, 25, 1327-1330. https://doi.org/10.7863/jum.2006.25.10.1327

[7] Nouriani, M., Felix, J.C. and Dubeau, L. (2002) Histogenesis and Histopathological Characteristics of Sertoli-Leydig Cell Tumors. CME Journal of Gynecologic Oncology, 7, 114-120. 